\title{
La trayectoria poética de Rubén Darío a la luz del parnasianismo. I: de Nicaragua a París
}

\author{
Miguel Ángel FERIA \\ UFR d'Études Interculturelles de Langues Appliquées. Université Paris Diderot-Paris 7 \\ miguelangelferia@gmail.com
}

\section{RESUMEN}

La trayectoria poética de Rubén Darío corre paralela al desarrollo intrínseco del modernismo, desde sus primeras tentativas románticas y parnasianas hasta la posterior asimilación de las novedades del decadentismo y el simbolismo. La lírica francesa del siglo XIX, y en concreto la escuela del Parnasse contemporain, jugó un papel fundamental en la génesis de la modernidad literaria en nuestras letras, en cuyo epicentro Darío encarnó todo el devenir del espíritu del Fin de Siglo. Partiendo de sus primeros balbuceos en Centroamérica hasta su crucial estancia en el París de 1893, donde se produjo su primer contacto cabal con el simbolismo, fue sin duda el parnasianismo la estética que, casi exclusivamente, configuró la voz poética del mayor de nuestros modernistas.

Palabras clave: Rubén Darío, Modernismo, fin de siglo, poesía, Parnasianismo.

\section{Rubén Darío's poetical path in the light of the parnasianismo. I: from Nicaragua to Paris}

\begin{abstract}
Ruben Darío's poetic career runs parallel to the intrinsic development of Hispanic Modernism, from his first Romantic and Parnassian attempts to his later assimilation of Decadentism and Symbolism novelties. $19^{\text {th }}$ century French lyric, and specifically, the Parnasse contemporain school played a fundamental role in the origins of literary modernity of Hispanic letters. In its epicenter, Darío represented the evolution of the Fin de siècle spirit. From his first steps in Central America to his important stay in 1893 Paris, where the first contact with Symbolism happened, Parnassianism was undoubtedly the aesthetics that, almost exclusively, shaped the poetic voice of our major Modernist.
\end{abstract}

Keywords: Rubén Darío, Hispanic modernism, Fin de siècle, poetry, Parnassianism.

\section{El aprendizaje de Rubén Darío en Centroamérica: la tutela de Modesto Barrios y Francisco Gavidia}

El gran mito de Rubén Darío (1867-1916) comenzó a fraguarse desde la más tierna infancia del hombre, allá en su Nicaragua natal, cuando apenas sabía hablar y ya asombraba a sus maestros y conciudadanos declamando versos de una corrección 
impropia para su edad. Sus estudios primarios los llevó a cabo en la escuela pública del licenciado Felipe Ibarra, entre 1874 y 1878, año en que pasó a formarse con los jesuitas, quienes le descubrieron y supieron transmitirle la veneración por la lírica española de los Siglos de Oro.

Con catorce años, en 1881, recibe las primeras nociones de lenguas y literaturas extranjeras a cargo de su profesor y mentor Modesto Barrios, una de las figuras capitales en su primer aprendizaje poético. Alentado por el maestro, Darío comienza a pergeñar sus primeros versos, fechados entre 1880 y 1882 , unos versos naturalmente adolescentes que proclaman a primera vista sus lecturas e influencias, la mayoría españolas: Quintana, Espronceda, Zorrilla, Núñez de Arce, algún premodernista como Manuel Reina. De aquellas primeras piezas -"Las tres" (1881) o "Serenata" (1882)- cabe destacar una manifiesta propensión a privilegiar los componentes plásticos y sensoriales y la temática orientalista, grecolatina y erótica: toda una serie de rasgos premodernistas que habían de preparar el terreno para la posterior asimilación del parnasianismo. Sin duda, esta proclividad respondía a la fascinación por las Leyendas de Zorrilla y por un alumno del vallisoletano como Manuel Reina, cuyos Andantes y alegros (1877) y Cromos y acuarelas (1878) se incardinaban en la tradición del romanticismo pintoresco, antecedente directo del denominado "colorismo andaluz".

Entre 1882 y 1883, Darío vivirá en El Salvador, donde habría de aprender la naturaleza del alejandrino francés de Víctor Hugo de la mano de Francisco Gavidia (1863-1955), nombre clave en la cultura salvadoreña de la época modernista. Poeta, filósofo, historiador, lingüista, pedagogo, en 1881 Gavidia había descubierto Les Châtiments (1853) de Victor Hugo, punto de partida de su preocupación por desentrañar la naturaleza del verso alejandrino del maestro francés y su consiguiente adaptación a la métrica castellana. Pronto puso en práctica sus investigaciones teóricas, y en 1882 tradujo "Stella" de Hugo siguiendo ciertos patrones versales radicalmente innovadores en el contexto hispánico ${ }^{1}$.

Si Gavidia fue el primero en estar en el secreto del nuevo alejandrino, no por ello lo guardó para sí, y en seguida se dedicó a hacer partícipes de su gran

1 El propio Gavidia lo explicaba pormenorizadamente en un importante artículo, "Historia de la introducción del verso alejandrino francés en castellano". Publicado originalmente en la revista salvadoreña La Quincena, año I, tomo II, $\mathrm{n}^{\circ} 19,1$ de enero de 1904. Más tarde volvió a editarse, con ciertas variantes, en Obras de Francisco Gavidia. Poemas y teatro (1913) y en el Boletín de la Biblioteca Nacional, $2^{\mathrm{a}}$ época, $\mathrm{n}^{\mathrm{o}} 12-13$, enero de 1934. Posteriormente ha sido recogido y comentado por Juan Felipe Toruño en Gavidia. Entre Raras Fuerzas Étnicas, pág. 41 y ss.; por Mario Hernández Aguirre en Gavidia. Poesía, literatura, humanismo, pág. 190 y ss.; y por José Salvador Guandique en Gavidia, el amigo de Darío, tomo I, pág. 75 y ss. Para un amplio y detallado análisis de los condicionantes prosódicos, acentuales, rítmicos y eufónicos del alejandrino gavidiano, remitimos al lector a dichas obras. 
descubrimiento a cuantos le rodeaban. Y entre éstos se encontraba un aplicado Rubén Darío, quien prestaría "una atención como yo deseaba; [...] y finalmente leyó él a su vez como yo mismo lo hacía [...] Nada había hasta allí en él de modernista; o mejor dicho de francés" (Guandique 1965: 75). El propio Rubén, años más tarde, no dudó en reconocer en su Autobiografia el lugar destacado que ocupó Gavidia respecto a la propia evolución de su concepción del verso: "de la lectura mutua de los alejandrinos del gran francés, que Gavidia, el primero seguramente, ensayara en castellano, surgió en mí la idea de renovación métrica, que debía ampliar y realizar más tarde".

Darío había llegado a San Salvador a mediados de agosto de 1882: tenía quince años, cuatro menos que Gavidia, quien rápidamente lo introdujo en los círculos intelectuales y políticos de la capital. Ambos comenzaron una suerte de revolución arremetiendo contra la literatura posromántica que había acaudillado en El Salvador un emigrado español, Fernando Velarde, y cuyo magisterio tenía anquilosada a la poesía de la República en los viejos dogmas retóricos y cívicos. Pese a todo, el premodernismo lírico de los jóvenes amigos se sustentaba únicamente en la búsqueda de una renovación exclusivamente métrica, pues el tono, la expresividad y los géneros temáticos de sus poemas se mantenían por entonces dentro de los límites del tardorromanticismo propio de la época.

Cuando en 1883 Darío abandona El Salvador, apenas se había atrevido todavía a ensayar el alejandrino francés en su lírica, cuya primera tentativa parece responder a la pieza romántica "Víctor Hugo y la tumba", escrita ya en Nicaragua hacia 1885. En efecto, tras su crucial estancia en la República vecina, en 1884 lo tenemos de vuelta en su país natal, trabajando en la Biblioteca Nacional de Managua, a la sazón dirigida por Modesto Barrios. A través de aquél, el joven poeta tuvo acceso a las últimas novedades de la literatura francesa, divulgadas por "La crónica parisiense" de La Ilustración Española y Americana y "La Chronique de la Quinzaine" de la parisina Revue des deux mondes. Período de lecturas febriles, la mayoría orientadas a París, Darío intenta penetrar en los secretos de la lengua francesa, que aún no domina, embriagándose en los libros que de Lamartine, Hugo, Théophile Gautier, Catulle Mendès o los Goncourt donaba puntualmente a la Biblioteca el cónsul francés en Nicaragua, Desiderio Pector. ${ }^{2}$

2 Diego Manuel Sequeira, en su obra Rubén Dario criollo, o Raíz y médula de su creación poética, aporta una lista de autores franceses cuyos ejemplares conserva todavía la Biblioteca Nacional de Nicaragua, explicitando además el año de edición de cada obra. En su "francés aprendido intuitivamente", según declara Sequeira, Darío pudo leer La vie et la mort d'un Clown (1879) de Catulle Mendès, y varios títulos de Gautier: Émaux et camées (edición de 1881), Spirite (1877), L'Orient (1877), Portraits contemporains (1874), Le Capitaine Fracasse (1880), Fusans et eaux fortes (1881), Voyage en Italie (1872), Histoire du Romantisme (1877) y Romans et contes (1880). También contaba la Biblioteca Nacional con antologías como la de P. Poitevin Petits Poetes français, depuis Malherbé jusqu'a nos 
Inestimable hubo de ser la ayuda que recibió de Barrios en su primera asimilación de la literatura francesa del XIX y de la poesía parnasiana en particular. En un artículo publicado años más tarde en Chile, "La literatura en Centro América", nos lo mentará Darío como "uno de los pocos escritores que allá tienen conocimiento y amor del estilo. Ama el arte, sabe escribir. Gautier ha tenido en él un traductor excelente y un buen seguidor"3. Y unos años más tarde, en 1893, aún incidirá en las mismas cualidades al recordar al profesor querido, aquél que "traducía a Gautier y daba las primeras nociones de modernismo" 4 . Alimentada por su tutor, la pasión de Rubén por la lírica francesa del período inmediatamente precedente tendrá inmediato reflejo en algunos de los versos que por entonces escribe. Entre romanticismos de variada tipología, el conocimiento, aunque limitado, de la poética parnasiana queda reflejado en ciertas estrofas -sobre todo en "A Emilio Ferrari, autor del poema Pedro Abelardo" (1884)- que incidían en una transposición artística tímidamente ya apuntada en sus primerísimas piezas.

Por esas mismas fechas Rubén Darío rinde un sincero homenaje a uno de sus referentes, Manuel Reina, con un artículo crítico y un poema. "Manuel Reina", prosa publicada en El Diario Nicaragüense el 4 de octubre de 1884 revela, a pesar de la juventud del poeta, a un atento crítico y a un lector perspicaz. Subrayando aquellos rasgos que en mayor medida convertían al poeta de Puente Genil en un colorista y un precursor del modernismo parnasiano, Darío celebra "sus versos, raudal de melodías derramadas, así como si fuera chorro de perlas de ánfora de limpio cristal, cayendo sobre alambres tenues de cítaras eólicas". El homónimo poema, por su parte, no era otra cosa que una versión métrica del ensayo, una teoría de la expresión poética de Reina en versos que la trataban de poner en práctica, emulándola.

Pero no será hasta finales de 1884 cuando Darío cite por vez primera en su obra a un parnasiano, exactamente al Gautier de Portraits contemporains y de Histoire du Romantisme, en su artículo "El último poema de Víctor Hugo": "El gran maestro, que decía Théophile Gautier, está ya en su ocaso. Que se descubriera algún elixir de vida para conservar al pontífice inspirado, al patriarca sublime!!!"5. Fue en aquellos Portraits contemporains donde el nicaragüense pudo recibir, nada menos que de mano de Gautier, amplias nociones sobre los Goncourt, Louis Bouilhet,

jours (1880) y con las colecciones de la Revue des deux mondes de 1880 a 1884.

3 Apareció originalmente en la Revista de Artes y Letras, 1888, tomos XI y XII. Recogido en Silva 1934: 186-212.

${ }^{4}$ Prefacio al libro de Jesús Hernández Somoza Historia de tres años de Gobierno Sacasa (1893). En Phillips, 1974: 121. Me ha sido imposible localizar ninguna de aquellas traducciones de Gautier firmadas por Barrios a las que alude Darío. Quizás se tratase de simples ejercicios privados que nunca vieron la luz.

${ }_{5}^{5}$ Publicado en El Porvenir de Nicaragua, $\mathrm{n}^{\circ}$ 116, 21 de diciembre de 1884, y recogido en Sequeira, 1945: 177-178. 
Glatigny o Baudelaire. Al año siguiente Darío, cuyo francés mejoraba poco a poco, publicó en El Porvenir de Nicaragua $-\mathrm{n}^{\circ}$ 5, 14 de junio de 1885- el cuento "A las orillas del Rhin", primera manifestación de la influencia de Catulle Mendès en su obra. Apenas tres meses más tarde, el 10 de septiembre de 1885, aparecía, también en El porvenir de Nicaragua, una traducción suya del cuento de hadas de Mendès "La llama azul" ". De aquellas primeras imitaciones y traducciones nos diría en Historia de mis libros que "fue Mendès mi verdadero iniciador, un Mendès traducido, pues mi francés era todavía precario". Ignoramos si con aquel "Mendès traducido" estaba refiriéndose Darío a sus propias versiones del parnasiano, esbozadas probablemente bajo la atenta supervisión de Modesto Barrios, o a los textos de Mendès que por entonces ya había vertido al español, por ejemplo, Manuel Gutiérrez Nájera en El cronista de México (1881). Sea como fuere, se abría en esta época una de las vías fundamentales que le llevarán a su modernismo: la prosa estilizada según los patrones de Catulle Mendès.

Tras Gautier y Mendès, uno de los primeros parnasianos en hacer acto de presencia en los escritos darianos fue François Coppée. De nuevo en El Porvenir de Nicaragua $-\mathrm{n}^{\circ} 22$, agosto de 1885-, y a propósito de "La pesca, de Núñez de Arce", Darío señalaba entre las posibles fuentes de dicho texto al célebre autor de $L e$ Passant, a quien considera por entonces un gran poeta: "Coppée en la actualidad es quien lleva el cetro de los poetas líricos de Francia. [...] Poeta lujoso y brillante, sus libros no faltan en los altos salones". Años más tarde su opinión de Coppée habría de variar radicalmente: en un artículo como "El Cristo de los ultrajes", por ejemplo, no ahorraba puyas contra el parnasiano, a quien juzgaría ya poco más que un "pobre viejo"7.

Para 1885, el niño prodigio de Nicaragua tenía listo su poemario de debut, Epistolas y poemas, que por una serie de avatares no vería la luz hasta 1888 con el rótulo accidental de Primeras notas. Pese a las nociones del Parnaso, exiguas aún, que Darío acumulaba en su haber, entre aquellos versos apenas puede espigarse una nota acorde con el ideal lírico de la Escuela. Un crítico como Diego Sequeira (1945: 73) señalaba ciertas semejanzas entre el retrato de Hugo que traza Darío en "Víctor Hugo y la Tumba" con aquél que Gautier había incluido en Fusains et eaux fortes (1880), "Un Buste de Victor Hugo". Por su parte, en la declamación romántica "Ecce homo" puede leerse una de las mot clef de la obra de Charles Baudelaire, spleen: "El spleen nos invade, nos sofoca, / esta tu humanidad se vuelve loca...".

6 "La petite flamme bleue" pertenece a la colección Les oiseaux bleus (1888). Suponemos que Darío lo habría leído en alguna de las publicaciones periódicas a las que Mendès entregaba sus textos antes de compilarlos en volumen, por ejemplo la Revue des deux mondes.

7 “El Cristo de los ultrajes" apareció por vez primera en la madrileña Revista nueva, $\mathrm{n}^{\circ}$ 2, agosto de 1899. 
¿Había leído Darío por entonces Las flores del mal? ¿Recogía el término del ensayo sobre Baudelaire que Gautier presentó en Fusains et eaux fortes? ¿O simplemente se hacía eco de una voz que, gracias al impulso baudelairiano, comenzaba a vulgarizarse hasta formar parte del léxico más esencial del Fin de Siglo hispánico? Descartada huella ni referencia alguna a Baudelaire en el primer Darío, lo más probable es que la hubiese leído, bien en Gautier, bien en algún otro texto de la época centrado en el autor de Les Fleurs du mal ${ }^{8}$.

Pese a todo, el único guiño al Parnaso que quedó expreso en Epístolas y poemas aparece en la dedicatoria a "Jerónimo Ramírez" colocada al inicio de "Alí", una leyenda de inspiración zorrillesca: "Siento que no haya resultado como yo quisiera...; pero desgraciadamente, no he podido encontrar en ninguna parte el haschis de Théophile Gautier. ¿Qué vamos a hacer!”. A no ser que estuviese refiriéndose literalmente al hachís en su estricta materialidad, una confesión como ésta nos lleva a reflexionar sobre la frustración del aspirante a moderno, sobre un joven Darío que intuye cuán benefactores para su inspiración lírica podían llegar a ser textos a los que todavía no había tenido acceso como Le Club des Hachichins, publicado por Gautier en la Revue des Deux Mondes en febrero de 1846. Situado justamente en la encrucijada que separa los caminos del romanticismo pintoresco de los del parnasianismo, este Darío premodernista comienza a comprender la distancia que va del orientalismo de Zorrilla a L'Orient de Gautier, obra que bien pudo haber leído en la Biblioteca Nacional de Managua.

Pronto, la intuición de Rubén alcanzará categoría de certeza cuando, durante su estancia en Chile a partir de junio de 1886, tenga la oportunidad de sumergirse a placer en las obras de los poetas del Parnasse contemporain. Ya nada volvería a ser lo mismo, y los Zorrilla y Manuel Reina no serán desde entonces más que un eco lejano de su aprendizaje poético, ahogado por una versión francesa más moderna y ajustada al ideal estético que el joven nicaragüense venía ensoñando desde tiempo atrás.

\section{Rubén Darío en Chile: Azul... (1888)}

El 23 de junio de 1886 el poeta desembarca en Valparaíso, dando así comienzo a su fecunda y trascendental etapa chilena. Un mes después ya lo tenemos en la capital, Santiago, trabajando en la redacción del diario La Época, donde publica sus primeros textos en aquel país y participa, con otros jóvenes del ramo, de un

${ }^{8}$ Gautier, en una pasaje del "Charles Baudelaire" integrado en Fusains et eaux fortes, se refiere a la acidia del poeta en estos términos: "Le dégoût et l'horreur des monstruosités modernes le jettent dans un spleen à faire paraître le sépulcral Young d'une gaieté folâtre...”. Por otro lado, ya el poeta zaragozano Eusebio Blasco había incluido en su segundo poemario, Arpegios (1866) una pieza de amor de signo posromántico titulada precisamente “Spleen”. Quizás fuese ésta la primera vez que el vocablo se emplease en español. 
cenáculo literario de escasa repercusión ${ }^{9}$. Pronto comenzó Darío a frecuentar a otros personajes de aspiraciones literarias similares a la suya y que jugarán un papel fundamental en su formación y en el encauzamiento de sus gustos estéticos. Una de las amistadas que más le marcaron en este sentido fue la de Pedro Balmaceda Toro, hijo del presidente de la República, José Manuel Balmaceda. En su prosa juvenil $A$. de Gilbert, Darío recordará, años más tarde, su llegada a Santiago de Chile y sus sueños cosmopolitas comunes con el malogrado Pedro, con quien ambicionaba visitar el París parnasiano de A. Silvestre y C. Mendès: “¡Iríamos a París, seríamos amigos de Armand Silvestre, de Daudet, de Catulle Mendès, le preguntaríamos a éste por qué se deja sobre la frente un mechón de su rubia cabellera; [...] y escribiríamos libros franceses!" 10 .

El joven Balmaceda poseía una considerable biblioteca en la que Darío tuvo acceso a múltiples volúmenes de la nueva literatura francesa, así como a publicaciones periódicas como la Nouvelle Revue o la Revue des Deux Mondes, donde venían apareciendo las últimas novedades literarias de París. Otras bibliotecas en las que Darío fue acrecentando el cúmulo de sus lecturas y su bagaje cultural fueron la propia Biblioteca Nacional de Santiago y la que su amigo Samuel Ossa Borne poesía en su domicilio, repleta de autores franceses contemporáneos Leconte de Lisle, Banville, Catulle Mendès...- cuyos libros fueron pasando de mano en mano por todos los amigos literatos de Rubén ( $C f$. López Morillas 1944: 914). Uno de ellos, Manuel Rodríguez Mendoza, rememoraba pasados los años cómo en casa de Samuel Ossa había tenido acceso por vez primera a los poetas del Parnasse contemporain, cuya rendida admiración hizo que pronto se les motejara él, a Darío, a Balmaceda y al resto de aquella troupe de "parnasianos o decadentes" (Vid. Silva 1966: 276).

De entre las grandes amistades que Darío cultivó durante su etapa chilena conviene señalar la del abogado y poeta de origen franco-canadiense Narciso Tondreau (1861-1949). Tondreau había dado sus primeros pasos en el mundo de las letras como traductor para La Época de algunos poetas franceses como Richepin. Según él mismo confesaba, fue a través de un comerciante francés, un tal Chopis,

${ }^{9}$ La Época, fundado en 1881 y dirigido por Eduardo MacClure, nació como un diario conservador que, tras la llegada de Darío, comenzó a dar cabida en su sección literaria a los autores más modernos tanto en lengua española -José Martí, S. Chocano, el propio Daríocomo en francés -Catulle Mendès-.

${ }^{10}$ Unos párrafos más adelante, Darío trae a colación una interesante anécdota en la que los dos jóvenes amigos discutían sobre sus ideales literarios. La postura del joven Darío en Chile era la de una férrea defensa del Parnaso, frente a la pronta desilusión de su amigo Balmaceda: "Basta de novelitas de Mendès de frases coloreadas, de hojarasca de color de rosa. El fondo, la base, Rubén, eso es lo que hay que ver ahora-. Yo quise persuadirle de que no arrojase su clámide para vestir el levitón del precepto. -Sé artista, no quieras ser sabio. Pinta, cincela...". 
que fue haciéndose con las novedades literarias importadas directamente de Francia, libros que en seguida compartía con el resto de jóvenes colaboradores de La Época (Cf. Uhrhan de Irving 1970: 883-892). Al calor de estos hallazgos se formó la tertulia en la que participaban los Darío, Tondreau, Balmaceda o Alberto Blest Bascuñan, hijo del gran prosista Blest Gana, mozo educado en París y cuya muerte le sobrevino prematuramente, como al propio Balmaceda. En el seno de aquella tertulia se comentaban "las obras o los poemas de Armand Silvestre, de Baudelaire, de Catulo Mendés; los "Poemas Bárbaros" de Leconte de Lisle, "Los Trofeos" de Heredia..." (Ídem: 883-892).

En opinión de Tondreau, fue en este ambiente de intercambio cultural en el que Rubén Darío descubrió realmente a los parnasianos y decadentes, y no durante su etapa en Centroamérica, de donde habría llegado adorando todavía a Hugo casi en exclusividad. Sería, pues, a partir del año de 1886, durante sus primeros meses en Chile, cuando el poeta nicaragüense amplió significativamente su abanico de lecturas e influencias francesas, impregnándose de las corrientes que en seguida confluirán en el modernismo de Azul... Sin embargo, a la altura 1887, y pese a mostrar ya en sus cuentos ciertas huellas del Parnaso, Darío escribiría aún algunos libros de versos como Abrojos, Canto épico a las glorias de Chile y Rimas, cuya expresividad denota la marca de los grandes poetas españoles del siglo XIX: Zorrilla, Campoamor, Núñez de Arce o Bécquer ${ }^{11}$. Paralelamente a estas obras de Darío, Narciso Tondreau dio a la imprenta su primer y único poemario, Penumbras (1887), muy influenciado también por el romanticismo europeo de Hugo, Musset o Bécquer. Darío le dedicó una reseña, "Apuntaciones literarias: Penumbras (Poesías de Narciso Tondreau)" -La Época, 14 de enero de 1887 (Silva 1934: 89-95)- donde,

\footnotetext{
${ }^{11}$ A la salida de Abrojos, Pedro Balmaceda publicó una reseña en la cual, tras apuntar los ecos de Bécquer, Musset o Heine, no dudaba en destacar que "Darío es el primer cantor de la nueva escuela que ha llegado a nuestras playas. F. Coppée, A. Silvestre, Arène y todos los parnasiens del gran barrio de París, si comprendiesen el español, dirían que Darío es un hermano" (Silva 1966: 177-178). Evidentemente, al expresar estos pensamientos, Balmaceda no aludía directamente a Abrojos, sino a toda la obra todavía inédita que su amigo escribía por entonces y que después habría de conformar $A z u l \ldots$ Tan sólo unos meses después de publicarse Abrojos, Rubén se presentaría a un certamen que buscaba "una colección de 12 a 15 poesías del género subjetivo de que es tipo el poeta Bécquer" y un "Canto épico a las glorias de Chile". Su canto cívico, dedicado al presidente de la República, José Manuel Balmaceda, mereció el primer premio. Por su parte, las Rimas, que obtuvieron una mención de honor, no acertaban en realidad a reproducir los medios tonos becquerianos, lo vago y sugerente del lirismo del poeta sevillano. En algunas de estas rimas asistimos, incluso, a un desarrollo embrionario de la concepción poética parnasiana: "En el libro lujoso se advierten / Las rimas triunfales: / Bizantinos mosaicos, pulidos / Y raros esmaltes, / Fino estuche de artísticas joyas, / Ideas brillantes; / Los vocablos unidos a modo / De ricos collares...".
} 
y pese a la naturaleza romántica del poemario, el nicaragüense sacaba a la palestra el nombre de los parnasianos. Estamos en enero de 1887 y Rubén cita por vez primera al gran patriarca del Parnasse, a propósito de unos versos de Tondreau cuya idea le parecía "digna de Leconte de Lisle". Tiempo de aprendizaje, de dudas, de tímidas osadías y de pasos en falso, son aquellos los meses en los que se puede comprobar con mayor nitidez la gestación, entre ayer y mañana, del modernismo en la obra de Darío, cuando el poeta recelaba aún de los aires de novedad franceses que venían a modular radicalmente la lengua poética de las Españas: "La tendencia generalizada es la imitación de escritores y poetas franceses [...], pero hágase el traje de las ideas con el rico material del español idioma"12.

En algunos poemas inéditos de aquel tiempo, Rubén prefigura una concepción de la lírica aún más cercana a los preceptos del parnasianismo francés. Así, en "El arte", publicado el 6 de diciembre de 1887 en La Época, el joven poeta asimila en sus versos los procedimientos del estatuario Nicanor Plaza, a quien va dirigida: "Tendedle vuestros mantos purpúreos y soberbios / a quien con sus escoplos dio sangre y vida y nervio / y el bronce de sus carnes al gran Caupolicán". Y por fin, el 7 de abril de 1888, Rubén publicó en La Libertad Electoral de Santiago de Chile su artículo "Catulo Mendez (sic), parnasianos y decadentes", en el que puede vislumbrarse una suerte de primerizo manifiesto modernista. Mostrándose plenamente consciente y partidario de la nueva estética, Darío alzaba la voz contra la autoridad académica en pro de una literatura de vanguardia de acento marcadamente francés. Comienza alabando la figura de Catulle Mendès, tanto en su papel de "rimador exquisito" como de "contador espléndido", y señalando de paso su parentesco familiar y artístico con la esposa, Judith, y con el eminente suegro, Théophile Gautier, a quienes Darío alaba sobremanera, para en seguida abordar el asunto principal del artículo, aquella nueva literatura que se dio en llamar "decadente".

En principio, no es sencillo para el nicaragüense trazar una clara delimitación entre el decadentismo y el Parnaso: "Ambos aman el símbolo, ambos prodigan la metáfora, ambos emplean vaguedades o plasticidades desusadas y mal vistas por

12 Junto a esta reseña, Darío escribió un prólogo para el segundo poemario de Tondreau, Asonancias, libro que nunca vería la luz. El paratexto de Rubén, sin embargo, ha sido publicado en varias ocasiones, y de él caben destacarse algunos juicios del poeta sobre la lírica de corte descriptivo de Tondreu, cercana, en su opinión, a la de un Loti, un Richepin o un Baudelaire. Sin embargo, y como sucede en la precitada reseña a Penumbras, Darío vuelve aquí a dejar algunas reflexiones sobre el verso francés y el español que denotan hasta qué punto andaba aún buscando el camino de la renovación poética de nuestro idioma: "En cuanto a sus metros [de Tondreau], son los hermosos metros castellanos, mil veces superiores a los franceses". Vid. "El libro Asonantes de Narciso Tondreau", publicado originalmente en la chilena Revista de Artes y Letras, 1889, tomo XIV (Silva 1934: 278295). 
varios grupos literarios...". El hecho de haber tomado como punto de partida a un autor de la naturaleza de su admirado Catulle Mendès bien puede explicar la confusión e indecisión dariana al respecto. Mendès, sobre todo el Mendès prosista, presentaba en sus cuentos y poemas en prosa una serie de innovaciones que se alejaban ya de la ortodoxia parnasiana, anticipando y participando de muchos rasgos propios del decadentismo. Pese a que el autor de La Légende du Parnasse contemporain siempre se consideró un parnasiano más, Darío, por todo ello, juzgaba que "Mendès [...] es de los decadentes", pues pretende "pintar el color de un sonido, el perfume de un astro, algo como aprisionar el alma de las cosas". Finalmente, Darío dejaba su juicio sobre la recepción de los parnasianos y decadentes en las letras hispánicas a la altura de 1887: "En castellano hay pocos que sigan aquella escuela casi exclusivamente francesa. Pocos se preocupan de la forma artística, del refinamiento [...]. Hay audaces, no obstante, en España y no faltan gracias a Dios- en América..." (Silva 1934: 166-172) ${ }^{13}$.

Este contexto denso y contradictorio explica muchas de las polémicas suscitadas por $A z u l \ldots$, el poemario que vino a prefigurar la estética del modernismo revolucionando todo el panorama literario hispánico. Impresa en Valparaíso el 30 de julio de 1888, la primera edición de $A z u l . .$. , un libro escrito simultáneamente a Abrojos y Rimas, explicitaba en su portada la división genérica de la obra en "Cuentos en prosa" y en los versos de "El año lírico", un conjunto dispar de textos que había venido publicándose en la prensa chilena entre el 7 de diciembre de 1886 y el 23 de junio de 1888. El prólogo de esta edición prínceps lo firmaba Eduardo de la Barra, y ya desde ese primer paratexto se advierte una ardiente polémica respecto a las novedades de $A z u l \ldots$ y sus conexiones con las corrientes literarias francesas ${ }^{14}$.

13 José María Martínez (1998: 95), por su parte, ha señalado una probable fuente del artículo de Darío en el ensayo "Symbolistes et décadents" de Maurice Peyrot, publicado originalmente en la Nouvelle Revue el 1 de noviembre de 1887. Allí, Peyrot detalla los rasgos fundamentales de las poéticas decadentes y simbolistas, citando y analizando a sus principales figuras, desde el precursor Baudelaire hasta Verlaine, Mallarmé, Moréas, Huysmans o incluso Rimbaud, de quien transcribe el soneto "Voyelles". Peyrot, además, acuña en una frase el término del que Darío se sirvió para bautizar el nuevo movimiento lírico americano: “C'est sans doute afin de prouver les idées plus modernistes peuvent être traitées en Style decadent que Stéphane Mallarmé...”. Todavía en otro artículo del 13 de julio de 1888 dedicado a Judith Gautier, ya divorciada de Catulle Mendès, se refería Darío a éste como "ese poeta rubio, decadente y simbolista", pasando por alto su condición de parnasiano. Cf. "Hija de su padre", originalmente en La libertad electoral (Silva 1966: 213 217).

${ }^{14}$ Eduardo de la Barra (1839-1900) fue el gran poeta del romanticismo chileno, traductor y teórico de la versificación castellana. Miguel Luis Rocuant le dedicó un capítulo en su obra Los líricos y los épicos. Poesía chilena (s.f.) donde afirma de él que "se dejó influir por las más diversas ideas literarias y filosóficas" y analiza y transcribe dos traducciones 
El primer rasgo de $A z u l . .$. que llamaba la atención del prologuista respondía a su esmerado formalismo, a la voluntad de hacer de la obra un "cofre cincelado" a la manera parnasiana, lo cual significaba ya su primer defecto: "El poeta tiene su flaco: esmalta y enflora demasiado sus bellísimos conceptos, abusa del colorete, del polvo de oro, de las perlas irisadas, de los abejeos azules...". A continuación, de la Barra pasaba a enumerar las fuentes principales: Hugo y la "secta moderna de los simbolistas y decadentes", "idólatras" y "neuróticos" acaudillados por "Catulo Méndes (sic)". Desde una postura conservadora, De la Barra se ciñe al propio artículo de Darío sobre "Catulo Mendez, parnasianos y decadentes", repitiendo sus indecisiones y aplicando sus premisas a los textos de $A z u l .$. Por un lado, el viejo veía con buenos ojos la influencia de Victor Hugo, pero aquella de Mendès era harina de otro costal, algo pernicioso de lo que estaba nutriéndose la mayor parte de la juventud literaria de América.

Como le ocurría a un gran sector de la crítica coetánea, sus ideas sobre la evolución de la poesía francesa desde el romanticismo no estaban del todo claras, y el parnasianismo, el decadentismo y el simbolismo se le aparecían así revueltos en una confusión terminológica y conceptual que él mismo venía a resumir con el motete de "poetas decadentes". Las nuevas aportaciones, reducidas a una "instrumentación poética" incomprensible y descabellada, se le representaban una simple "patología literaria”; y todo para terminar preguntándose: “¿Es Rubén Darío decadente? Él lo cree así; yo lo niego". De la Barra ve en Darío mayormente a un parnasiano que siente "las atracciones de la forma" pero que aún no se ha dejado embaucar del todo por las "extravagancias características de la escuela decadente"; una materialización hispánica del engranaje estético que representaba como ningún otro el propio Catulle Mendès: "De [Darío] diremos, como él de Cátulo Méndez, que es un poeta de exquisito temperamento; [...] como Gautier, su suegro, es un parnasiano, pero con ribetes de simbolista decadente". El prólogo de Eduardo de la Barra acabó disgustando a Rubén Darío, a tenor de las "Notas" incluidas en la segunda edición de $A z u l . .$. , muchas de las cuales vienen a contradecir al poeta chileno y a aclarar algunos conceptos aquí planteados.

Mucho se ha insistido en el carácter estrictamente renovador de la prosa de $A z u l \ldots$, en detrimento de su poesía ${ }^{15}$. Bien es cierto que, por más que la obra

parnasianas de De la Barra que consideraba inéditas, "El vaso roto" de Sully-Prudhomme y "Antonio y Cleopatra" de Heredia. A ellas debe sumarse la traducción de "La víspera" de Heredia que el poeta chileno presentó en 1893 en la Revista Puertorriqueña. La amistad entre Darío y de la Barra se remonta a los primeros días del nicaragüense en Chile, cuando gustaba frecuentar la casa del viejo poeta y sobre todo su nutrida biblioteca, colmada de libros franceses modernos. Pese a todo, Eduardo de la Barra no rebasó nunca los límites del romanticismo en su poesía, y siempre que pudo se manifestó contrario a las mayores innovaciones modernistas.

${ }^{15}$ Ya el propio Juan Valera, en la segunda de sus "Cartas americanas", publicada en El 
carezca de prefacio alguno donde el propio Darío se posicione estéticamente, y pese al confuso prólogo de Eduardo De la Barra, es claramente la sección de "Cuentos en prosa" aquella en la que puede advertirse con mayor amplitud y a primera vista el afán innovador y la huella del parnasianismo en el primer libro modernista del nicaragüense. En esto no se separaba un ápice Rubén de aquellos modernistas que le precedieron en Hispanoamérica tal J. Martí, Gutiérrez Nájera o Julián del Casal, en cuya creación prosística, con anterioridad al verso, puede percibirse la influencia de los Gautier, Mendès, Goncourt o Flaubert. Traducciones de estos autores aparecían a lo largo y a lo ancho de todo el Continente, y en este sentido Santiago de Chile no fue una excepción. El mismo año de $A z u l . .$. , por ejemplo, vio la luz en dicha ciudad el volumen de Gautier El perrito de la marquesa, en una versión anónima que incluía los cuentos "El vellocino de oro" y aquel que da nombre al tomo. Las descripciones de objetos artísticos y suntuosos, escenas de ninfas o poetas hambrientos que allí se integran guardan, como bien ha señalado Silva Castro (1934: LXXVII-LXXXI), semejanzas "nada vulgares" con ciertos pasajes de

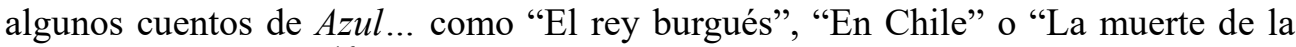
emperatriz de China"16.

La motivación definitiva que empujará a Darío a refinar estéticamente su literatura y a adoptar algunas técnicas completamente novedosas en el contexto

Imparcial el 29 de octubre de 1888, opinaba que "en la prosa hay más riqueza de ideas; pero es más afrancesada la forma. En los versos, la forma es más castiza. Los versos de usted se parecen a los versos españoles de otros autores...”. Enrique Anderson Imbert (1952: XIV) explicaba la mayor novedad de la prosa de $A z u l . .$. en estos términos: "[Darío] era tímido y, antes de decidirse, esperaba a que le dieran una señal. Había visto triunfar la prosa artística en Gautier, Flaubert, los Goncourt, Saint-Victor, Mendès y Loti. En América, los primeros signos de este cambio habían aparecido también en prosa. Y le pareció seguro estrenarse en prosa. Quizá estimara en sí mismo más al versificador que al prosista; y se arriesgó a experimentar con lo que le interesaba menos...".

16 No resulta nada improbable que Darío hubiese leído esta traducción anónima de Gautier, y que quedara fascinado. Ahondando en esta cuestión, Silva Castro (1934: LXXVII) señala el parecido de algunas frases de Gautier, como "Los montantes de las puertas, pintados a la aguada en lila suave, representa aventuras mitológicas y galantes", con otras de Darío tal “...el salón de los tiempos galantes, con cuadros del gran Watteau y de Chardin...". Empero, y sin negar a priori la hipotética intertextualidad, no debe obliterarse el contexto literario general en el que se escribió Azul... ni la condición esencialmente poligenética de la obra de Darío. Así, estas descripciones de estancias suntuosas y japonerías bien pueden no haber partido de texto alguno de nadie en concreto, y a la misma vez de todos: de los hermanos Goncourt, de Gautier o de algunas obras de su hija Judith que Darío conocía bien como Le livre de jade o Le dragon imperial. Incluso podían deberse a la observación directa de aquellos salones orientalizantes que adornaban los domicilios de Pedro Balmaceda Toro o Carlos Toribio Robinet, en los que Darío soñaba con un lujo fuera de su alcance. 
hispánico le vendría principalmente de la lectura de Mendès, cuyos cuentos y poemas en prosa le sirvieron de patrón. Como ha señalado R. Llopesa (1995: 13), "la prosa anterior a $A z u l . .$. no puede considerarse prosa modernista, como tal, por carecer de los recursos y la estética que encontramos [en Mendès]". Capitales para el nacimiento de la prosa modernista y, en particular, del poema en prosa en lengua castellana fueron los Pétits poèmes en prose que el francés integró en su libro de cuentos La chanson qui rêve (1886). Más allá de su materialización formal, la prosa de Mendès y de otros parnasianos como A. Silvestre prefigura una serie de elementos en su contenido que habrán de pasar directamente a aquellos remedos del conte parisien trazados por Darío, tales el rol del poeta en la sociedad burguesa, el perfil de sus personajes principales, la mayoría artistas jóvenes de la gran ciudad cuyas aventuras se desarrollaban en ambientes lujosos y elegantes, y un erotismo bien explícito ${ }^{17}$.

Las huellas que del Parnasse pueden rastrearse en los versos de Azul... y que conforman "El año lírico", si bien suelen mostrarse mucho más sutiles y difusas que

${ }^{17}$ Un cuento como "La ninfa" guarda, en este sentido, innegables paralelismos con "Lesbia", de C. Mendès, tanto en el plano formal y estilístico como en el argumental, desde el refinamiento del ritmo y su flexibilidad musical, la brevedad y concisión de oraciones y descripciones, la plasticidad y los juegos cromáticos y sinestésicos, las aliteraciones e iteraciones, hasta la sensualidad e incluso el nombre y el carácter del protagonista femenino. El propio Darío confesaba en Historia de mis libros que para "La ninfa", "los modelos son los cuentos parisienses de Mendès, de Armand Silvestre, de Mezeroi...". Sin embargo, a la hora de abordar los contenidos eróticos, el nicaragüense no siguió a pies juntillas la estela de dichos autores. Tal como ya señalara con acierto Erwin K. Mapes (1925: 40), en Mendès y Silvestre el sentimiento amoroso es puramente físico, "chez Mendès, toujours élégant, chez Silvestre très souvent d'une grossièreté dégoûtante", mientras que en Darío, por el contrario, la sexualidad "a toujours quelque chose de religieux". Análogas coincidencias pueden señalarse entre "El palacio del sol" de Darío y algunos de los cuentos y "Pétits poèmes en prose" de La chanson qui rêve de Mendès -"Martine et son ange" y "Le jardin des jeunes âmes" fundamentalmente-. En cuanto a las evocaciones plásticas del paisaje urbano que Darío agrupa en el “Álbum porteño”, ya José María Martínez (1998: 221) subrayó su ascendencia directa en los textos que Mendès incluyó en Las folies amoreuses (1877) bajo el epígrafe de "Imaginerie parisiense": "L'Impasse. Eauforte", "Le chaval et le cavalier. Dessin à la plume" y "Les balcons roses. Sanguine". Por lo que respecta a las fuentes parnasianas de «El velo de la reina Mab», E. K. Mapes (1925: 44) trajo a colación « La peau de tigre » de Théophile Gautier, "Les Dons des fées" de Baudelaire y algunos pasajes de Catulle Mendès en los cuales asoma la misma la aparición de un Hada sobre fantástica cabalgadura: "L'Almanach" - Pour lire au lit- y "La visitation" -Hesperus-. Por su parte, en "El rubí" Darío incluye la figura de un gnomo llamado "Puck", personaje central de algunos cuentos de Mendès como "Le ramasseur de bonnets", "Puck dans 1'orgue de Barbarie" o "Le lit enchanté". La morada del gnomo, una gruta recamada de piedras preciosas, parece inspirarse igualmente en otro texto de Mendès, "Fleurs et pierreries". 
en la prosa, no por ello resultan menos significativas. Más allá de cualquier intertextualidad, quizá la primera de las novedades que de las poesías del libro de 1888 deba destacarse por su filiación parnasiana estriba, a grandes rasgos, en la ausencia del tono confesional y elegíaco propio del romanticismo y el posromanticismo hispánicos. Más que a una revolución en lo formal, asistimos en Azul... a una revolución en lo anímico, y frente a la sentimentalidad del paisaje romántico, la naturaleza, eje fundamental de "El año lírico", exhibe en todo su esplendor físico su apariencia más benefactora y sensual, más concreta y objetivable.

La búsqueda de la belleza y el amor bajo un relente pagano ha venido a sustituir a aquellas angustias y melancolías del período anterior: a Lamartine, Gautier; a Musset, Thédodore de Banville. La misma estructuración en cuatro poemas estacionales bien pudo haberla tomado Darío del propio Banville, quien en la tercera edición del Parnasse contemporaine (1876) hizo lo propio con "Le Printemps", "L'Eté", "L'Automne" y "L’Hiver". "Primaveral" es la versión rubendariana del idilio banvillesco: ya algunos rasgos de la métrica, como el estribillo exclamativo - ¡OOh amada mía! Es el dulce / tiempo de la primavera”-, están presentes en "Le Printemps" -“Te voilà, rire du Printemps!"-. Algunos motivos de "Primaveral", como el de la urna cincelada con detalles helenísticos, provienen evidentemente de la tradición parnasiana: "Mi dulce musa Delicia / Me trajo un ánfora griega / Cincelada en alabastro...". La invocación de la belleza clásica y de la lengua griega "que en glorioso tiempo antiguo / Pan inventó en las florestas" remite directamente al Banville de Les Exilés y del prefacio a La sang de la coupe, al Gautier de "Bûchers et tombeaux" -Émaux et camées-, y a todo el helenismo parnasiano en general, con su revitalización de los mitos paganos y de una sensualidad vitalista y arcádica.

Mayores trazos parnasianos presenta aún "Estival", sin duda la composición poética de $A z u l . .$. que se ajusta con mayor fidelidad a los dogmas de la Escuela. Su severidad formal y ciertos detalles en su contenido como el exotismo, la violencia animal y la visión negativa del imperialismo británico invocan la lírica de Leconte de Lisle y traen a la memoria muchos pasajes de los Poèmes barbares donde el antropomorfismo animalístico, la descripción plástica y detallista de la naturaleza salvaje y las escenas de caza guardan estrecha relación con la visión dariana $(C f$. Revel 1942: 88 y ss. $)^{18}$. Los otros dos poemas de "El año lírico", "Autumnal" e

${ }^{18}$ En su prólogo, Eduardo de la Barra opinaba ya que "la pintura del tigre es a la manera de Leconte de Lisle", pese a ciertos errores en la ambientación, impropios del maestro del Parnaso, que comete Darío, como el haber situado la escena en África en lugar de la India, o el incluir la presencia, forzada por la rima consonante, de un "kanguro" en dicho continente. Algunos de estos deslices fueron en seguida subsanados por el poeta, y para la segunda edición del libro, el propio Darío escribe en una de sus "Notas" finales que "está atendido lo 
"Invernal", remiten por su parte al subjetivismo asordinado y galante del Parnaso menor, común a los Coppée, Mendès o Armand Silvestre ${ }^{19}$. Escasas fueron las traducciones firmadas por Darío, y la única que se incluye en $A z u l \ldots$ es precisamente "Pensamiento de otoño" de Armand Silvestre, publicada originalmente en La Época el 15 de febrero de $1887^{20}$. Finalmente, la última de las

indicado por el prologuista". Así, donde antes ponía "selva africana" se lee "selva indiana" en la edición de 1890, si bien el mentado "kanguro" asoma todavía "por el ramaje oscuro". Pese a todo, el nicaragüense negó rotundamente, y por partida doble, cualquier filiación entre "Estival" y su admirado Leconte de Lisle. En otra de las notas que adjunta al poema en la segunda edición afirma que "mucho tiempo después de la publicación de Azul... llegaron a mis manos las Odas bárbaras de Leconte de Lisle y entre ellas me llamó la atención "El sueño del jaguar". Encontré, holgándome de ello, una coincidencia, aunque lejana, entre esa obra del maestro y la humildísima "Estival" mía". Y aún en Historia de mis libros perjura Rubén que "algún escaso lector de tierras calientes ha querido dar a entender que ¡tratándose de tigres!- mi trabajo podía ser, si no hurto, traducción de Leconte de Lisle. [...] Ello me hizo sonreír...". Podemos creer los argumentos de Darío, achacando a una simple coincidencia las similitudes entre ambos poemas. Si no mentía, si es cierto que sólo "mucho tiempo después" tras la publicación del Azul... de 1888 tuvo acceso a los Poèmes barbares cuyo título confunde en 1890 con las Odas bárbaras del italiano Carducci-, estaríamos ante una de tantas analogías, nada infrecuentes, entre autores de una misma época que se desconocen mutuamente. Signos epocales. Aunque también pudiera darse el caso, nada improbable, de que Rubén hubo llegado a recrear motivos tan propios de Leconte de Lisle por vías secundarias, bien por traducciones o imitaciones hispánicas de sus poemas, bien por reseñas o ensayos sobre el poeta francés en los que se diseccionara su lírica y que le habrían servido de punto de partida. Sea como fuere, cuando Rubén está escribiendo su poema conoce ya al autor de los Poèmes barbares, a quien cita por vez primera, recordemos, en enero de 1887. Y en esa misma edición segunda de $A z u l . .$. en la que negaba el parentesco de "Estival" con Leconte de Lisle no dudó en incluir un soneto dedicado precisamente al maestro parnasiano.

${ }^{19}$ Ya José María Martínez (1998: 265) ha señalado acertadamente la influencia de A. Silvestre en ambas piezas, basándose, para ello, en ciertas pistas léxicas tal la inclusión de palabras de extraña etimología como "volúbilis", término que el nicaragüense había tomado prestado de un poema de Silvestre, "Pensée d'Automne" - Roses d'Octobre-. E. K. Mapes (1925: 97) ha querido ver la huella de Leconte de Lisle en "Autumnal" alegando ciertas semejanzas entre la descripción de las flores del poema rubendariano -“...la rosa virgen, / la blanca margarita, / la azucena gentil, y las volúbilis / que cuelgan de la rama estremecida" y aquella llevada a cabo en "Çunacépa" -Poèmes antiques-: "la liane aux cent noeuds étreint les rameaux lourds, / et laisse, du sommet des immenses feuillages, / pendre ses fleurs de pourpre au milieu des herbages...".

${ }^{20}$ Con anterioridad, La Época había anunciado, en su número del 16 de noviembre de 1886, la inminente publicación de un libro de Darío, El rey burgués, obra que supuestamente llevaría "como introducción varios juicios y apreciaciones [...]. Entre éstos figurará una carta de Armand Silvestre, muy honrosa para el señor Darío" (Silva 1934: 255). La 
poesías que Darío incluye en el Azul... de 1888, "Anagké”, denota en mayor medida la lectura y asimilación de Víctor Hugo antes que la de cualquier parnasiano.

La fama de $A z u l \ldots$ no fue inmediata, y sólo a raíz de la publicación en $E l$ Imparcial de las dos célebres "Cartas americanas" de Juan Valera -22 y 29 de octubre de 1888-, comenzó a despertar interés y a ser leído con intensidad. En este sentido, Darío se mostró muy espabilado y un excelente divulgador de su obra, no dudando en enviarla, con amables dedicatorias, a personalidades de la talla de Valera o Menéndez Pelayo en España, estrategia que posiblemente repitió con sus venerados C. Mendès o A. Silvestre en París. El joven poeta era consciente de que un juicio favorable de tan eminentes firmas le abriría muchas puertas, y así lo demuestra el uso que le dio luego a aquellas cartas de Valera, una suerte de dorada credencial con la que presentarse al mundo de las letras españolas. Las misivas de Valera suponen el punto de partida en la recepción de uno de los libros capitales del modernismo, y un valioso documento que luego tendrían en cuenta muchos de los que se acercaron después a reseñarlo. En la primera carta, la del 22 de octubre, Valera acuña el sintagma "galicismo de la mente", que de tan buena fortuna gozaría entre los críticos de Darío. Aunque "perfecto y profundo", este galicismo fue la característica primaria y definitoria que Valera resaltaba de $A z u l . .$. , signándolo así con una indeleble heráldica francesa que en seguida se convertirá en santo y seña de todo el modernismo hispánico, para mal y para bien:

Leídas las 132 páginas de $A z u l \ldots$, lo primero que se nota es que está usted saturado de toda la más flamante literatura francesa. Hugo, Lamartine, Musset, Baudelaire, Leconte de Lisle, Gautier, Bourget, Sully-Prudhomme, Daudet, Zola, Barbey d'Aurevilly, Catulo Mendès, Rollinat, Goncourt, Flaubert y todos los demás poetas $\mathrm{y}$ novelistas han sido por Ud. bien estudiados y mejor

susodicha carta de Silvestre nunca se publicó, y todavía hoy permanece inédita. Cabe la posibilidad de que el poeta francés se la enviase a Darío agradeciéndole su traducción de "Pensée d'Automne". Uno de los amigos chilenos de Rubén, Manuel Rodríguez Mendoza, le envió una carta a El Salvador, fechada en julio de 1889 -y publicada luego en $E l$ Imparcial de Guatemala el 3 de noviembre- en la cual le preguntaba si en Centroamérica "saben que Armando Silvestre, Leopoldo Alas, la señora Pardo Bazán [...] son tus amigos, y los unos te llaman hermano, y los otros su igual, y todos te aplauden..." (Sequeira 1964: 106). Esta supuesta "amistad" entre Darío y Silvestre se restringe, probablemente, a aquella carta, a una simple nota cordial: la primera vez que apareció el cuento "El rubí" en $L a$ libertad electoral de Santiago de Chile -9 de junio de 1888- incluía esta dedicatoria de Darío: "A Armand Silvestre, en pago de una frase bondadosa". Hacia el final de su vida, la percepción que Darío tenía de Silvestre había cambiado significativamente, aunque no por ello le negara el fiel elogio. Así leemos en Historia de mis libros: "Bien es sabido que, a pesar de sus particularidades harto rabelesianas y de su excesiva galoiserie, Silvestre era un poeta en ocasiones delicado, fino y sentimental". Para un análisis comparativo entre "Pensée d'Automne" y "Pensamiento de otoño", vid. Llopesa, 1992: 209-215. 
comprendidos. Y Ud. no imita a ninguno: ni es Ud. romántico, ni naturalista, ni neurótico, ni decadente, ni simbólico, ni parnasiano. Usted lo ha revuelto todo: lo ha puesto a cocer en el alambique de su cerebro, y ha sacado de ello una rara quintaesencia.

Pese al alambicamiento y al sincretismo que Valera, con indudable perspicacia, atribuye a la génesis del modernismo rubendariano, no tardó sin embargo en reconocer la preeminencia de la parnasiana entre las corrientes francesas allí confluyentes:

Todo está cincelado, burilado, hecho para que dure, con primor y esmero, como pudiera haberlo hecho Flaubert o el parnasianismo más atildado. [...] Si se me preguntase qué enseña su libro de usted y de qué trata, respondería yo sin vacilar: no enseña nada, y trata de nada y de todo. Es obra de artista, obra de pasatiempo, de mera imaginación. ¿Qué enseña o de qué trata un dije, un camafeo, un esmalte, una pintura o una linda copa esculpida?

No le faltaba razón a Juan Valera, y ni tan siquiera el propio Rubén Darío habría de desmentirle, al contrario. En su célebre artículo publicado en La Nación de Buenos Aires en 1896, "Los colores del estandarte", el poeta reafirma con rotundidad la condición parnasiana de la obra:

El $A z u l \ldots$ es un libro parnasiano, y, por lo tanto, francés. En él aparecen por primera vez en nuestra lengua el "cuento" parisiense, la adjetivación francesa, el giro galo injertado en el párrafo clásico castellano; la chuchería de Goncourt, la calinerie erótica de Mendès, el escogimiento verbal de Heredia, y hasta su poquito de Coppée ${ }^{21}$.

Todavía en Historia de mis libros, ya tardíamente y cuando nada tenía que ganar ni que perder, Rubén Darío resaltaba aún la trascendencia exclusiva de la literatura parnasiana en la genealogía de su revolución modernista:

¿Cuál fue el origen de la novedad? El origen de la novedad fue mi reciente conocimiento de autores franceses del Parnaso, pues a la sazón la lucha simbolista comenzaba en Francia y no era conocida en el extranjero, y menos en nuestra

21 Entre los rasgos parnasianos que Rubén destacaba de Azul..., no deja de resultar significativo que él mismo resalte, con agudeza, la "adjetivación francesa" y "el escogimiento verbal de Heredia", pues en efecto sobre estos principios se asienta gran parte de la revolución lingüística del modernismo. Su renovado método de adjetivación y selección léxica supuso un radical abandono de los clichés de la poesía tradicional española, cuya lengua estaba por entonces camino de una perniciosa fosilización: por ese flanco le lloverían a Darío las mayores críticas, por su afán de ampliar con valentía el diccionario y de adaptar al español el adjetivo enfático, pintoresco y vigoroso del parnasianismo. 
América. Fue Catulle Mendès mi verdadero iniciador, un Mendès traducido, pues mi francés todavía era precario. Algunos de sus cuentos lírico-eróticos, una que otra poesía de las comprendidas en el Parnasse contemporaine, fueron para mí una revelación. Luego vendrían otros anteriores y mayores: Gautier, el Flaubert de $L a$ Tentation de de St. Antoine... [...] Ese primer libro [...] se componía de un puñado de cuentos y poesías que podrían calificarse de parnasianas.

¿Exageraba Rubén privando al simbolismo de todo influjo en el nacimiento del modernismo, al menos en su concepción del mismo? Probablemente no, si tenemos en cuenta que, a la altura de 1888, los escasos rudimentos simbolistas y decadentes que conocía y que había expuesto en el precitado ensayo "Catulo Mendez, Parnasianos y decadentes" procedían principalmente de su lectura de las prosas del poeta bordelés. José María Martínez (1998: 51-52) plantea la hipótesis según la cual habrían sido una serie motivos relacionados con el público los que en principio empujaron al poeta a ocultar los atributos decadentes y simbolistas de $A z u l \ldots$ : para Martínez, Darío pudo "tener miedo a ser tachado de decadente al comienzo de su carrera" por un grupo de lectores contagiado de "prejuicios literarios y extraliterarios hacia la décadence, y más acostumbrado al prestigio de Víctor Hugo y al buen nombre de los parnasianos". No estoy de acuerdo con la sugerencia de Martínez, en primer lugar, porque no es cierto que los parnasianos tuvieran tan "buen nombre" cuando Darío publica su obra, pues un gran sector del público, la crítica e incluso muchos autores condenaban, con honrosas excepciones, al Parnaso al mismo cajón de sastre donde se confundía con el decadentismo y el simbolismo. Y en segundo lugar, el hecho de que Rubén siguiera calificando a $A z u l \ldots$ de libro parnasiano hasta el final de su vida no puede deberse, como opina Martínez, a "simples deslices de la memoria al volver sobre el libro años más tarde". Teniendo en cuenta la propaganda, a veces subrepticia y otras completamente explícita, a la que Darío recurrió siempre para definirse a sí mismo como el verdadero padre y difusor del modernismo hispánico, y si a ello sumamos la autoridad absoluta que el simbolismo, frente al desprestigio del parnasianismo, había adquirido justo en la segunda fase del modernismo, ¿no sería más lógico que Darío aprovechase sus memorias para proclamarse con $A z u l . .$. el introductor del simbolismo en América si de verdad consideraba que allí había recogido algunas de sus fórmulas? No negamos que el Rubén de Chile desconociese absolutamente a los decadentes y simbolistas: sí que los hubiese asimilado de manera cabal y que en el $A z u l \ldots$ de 1888 haya un reflejo de su supuesta lectura. Si Darío entendió siempre su Azul... dentro de los márgenes del parnasianismo no fue ni por ganarse inicialmente el favor de los lectores ni por padecer una ráfaga de alzheimer al final de sus días, sino porque de verdad y en consecuencia así lo creyó.

El 9 de febrero de 1889 Darío abandona Chile para siempre y toma el camino de regreso a Centroamérica, dando comienzo a otra etapa en la que habrá de mostrarse más partidario que nunca de los principios del parnasianismo: la segunda edición de Azul... (1890), editada en Guatemala, así lo confirma. 


\section{Regreso a Centroamérica. Segunda edición de $\boldsymbol{A z u l . . . ~ ( 1 8 9 0 )}$}

Tras los años chilenos, comienza luego un incesante periplo centroamericano que habrá de llevar al poeta el 6 de marzo de 1889 a su Nicaragua natal, para en seguida partir hacia El Salvador, Guatemala, Costa Rica y de nuevo Guatemala. Rubén Darío regresa a El Salvador el 1 de mayo 1889, y allí se reúne en seguida con su viejo amigo Francisco Gavidia, quien lo saluda con un extenso artículo en el Repertorio Salvadoreño ${ }^{22}$. Por mediación de su protector, Darío fue nombrado director de La Unión, diario oficioso del gobierno de Francisco Menéndez Valdivieso, una publicación de la que se sirvió ampliamente para publicitar la inminente salida de una segunda edición de $A z u l . .$. Entre las dos ediciones, Darío compuso entretanto una serie de piezas de indudable raigambre parnasiana, algunas luego descartadas del Azul... de 1890: son los casos del soneto "El minué", fechado en "San Salvador, 14 de julio de 1889", o "El humo de la pipa", cuento que recuerda, por título y contenido, a "La Pipe d'Opium" de Gautier ${ }^{23 .}$

El 22 de junio de 1890, antes de que pudiera editarse la nueva edición de $A z u l \ldots$, el general Carlos Ezeta daba un golpe militar que derrocaba al presidente Menéndez, protector del poeta nicaragüense durante su estancia en El Salvador; un hecho que le obligaría a huir apresuradamente a Guatemala, adonde llega el 30 de junio de ese año con la segunda edición de su Azul... lista para imprimirse. En la capital guatemalteca, entraría pronto en contacto con los principales círculos literarios, trabando amistad con personalidades como las del exiliado cubano José Joaquín Palma, Francisco Lainfiesta y un jovencísimo Enrique Gómez Carrillo. Su firma comienza a aparecer con asiduidad en revistas y diarios, incluso consigue dirigir uno de los periódicos de mayor divulgación, El Correo de la tarde.

Según reza su colofón, el segundo $A z u l . .$. se imprimió definitivamente el 4 de octubre de 1890, en una versión con importantes cambios respecto a la de Valparaíso. El primero de ellos atañe a los paratextos críticos, pues se incluyen ahora las célebres cartas de Juan Valera precediendo al prólogo de Eduardo de la Barra, así como una serie de interesantísimas "Notas" finales de Darío a sus propias composiciones. Por otra parte, nuevas prosas y poemas se intercalan entre los que

${ }^{22}$ Allí, Gavidia desentrañaba el ideal artístico de Darío a la luz de sus "maestros", entre los que destacaba a Victor Hugo, Zola, Dumas hijo, Flaubert, Guy de Maupassant, Catulle Mendès o Richepin. Luego, al analizar el carácter de los versos de Azul..., se sirvió de una retórica parnasiana que sin duda haría las delicias del Darío de 1889: "Sus versos son cadenas de flores, sinfonías de órgano, risa de teclado, la inmensa tiranía de la dulzura, [...] columnas del Partenón, las ansas en forma de pecho de bacante de las cráteras griegas, las copas de Benvenuto Cellini..." (Sequeira 1964: 24-35).

23 "La pipa de opio" había sido ya traducida al español por el argentino Carlos Olivera en 1878. Para un detallado análisis de "El humo de la pipa" de Darío, remitimos a Sellés, 2002: 41-45. 
conformaban la primera edición, y a este respecto debemos apuntar una consciente y significativa intensificación del parnasianismo ya notorio en el libro de 1888. Los cuentos añadidos ahora, "La muerte de la Emperatriz de China", "A una estrella" o "El sátiro sordo" engarzan con la literatura francesa de la época parnasiana, y sobre todo con el indiscutible maestro de la prosa dariana, Catulle Mendès. El propio poeta nos lo confesaba en Historia de mis libros: "el procedimiento es más o menos mendesiano (sic), pero se impone el recuerdo de Hugo y de Flaubert...". En cuanto a los nuevos poemas, y exceptuando "A un poeta", imitado del célebre "A Gloria" del mexicano Salvador Díaz Mirón, así como la mediocre serie de "Echos", compuesta en francés, las dos secciones principales de 1890, "Sonetos Áureos" y "Medallones", se incardinan en la tradición más ortodoxa del Parnasse contemporain.

En los "Sonetos áureos" y en los "Medallones" cristaliza definitivamente en la poesía de Rubén Darío el alejandrino francés que había aprendido en El Salvador de la mano de Francisco Gavidia. Los motivos, los temas, la expresividad denotativa, más plástica y estática que discursiva, y, en fin, algunas de las fuentes implícitas y explícitas de cada texto indican que el Darío de 1890 quería lucir, como nunca antes ni después lo hiciera, las preseas de un poeta parnasiano. Dejando aparte "Venus", ostentación de una subjetividad doliente, "Caupolicán" no es otra cosa que un poème barbare, que un trophée, que un bajorrelieve digno de Leconte de Lisle o José María de Heredia ${ }^{24}$. Por su lado, "De invierno. Acuarela" desarrolla una escena de amor galante, ambientada en un boudoir suntuoso y parisino que no desentonaría en los libros de Armand Silvestre o Catulle Mendès ${ }^{25}$.

Si la mayoría de los poemas chilenos del ciclo de Azul... remitían a un

${ }^{24}$ Para un extenso análisis de "Caupolicán” a la luz del parnasianismo, $c f$. Pérez, 1992: 483-494. Allí, el crítico se centra en estudiar mayoritariamente la condición de "sutil artefacto cultural" de un poema de naturaleza parnasiana como éste, atendiendo al sujeto lírico impersonal y a las técnicas descriptivas empleadas por el Darío más deudor de la Escuela.

${ }^{25}$ La poetización de lo cotidiano presente en "De invierno" engarza con una tradición romántico-parnasiana que podría remontarse a ciertos poemas de Nerval como "La cousine". Armand Silvestre, en La Chanson des heures o Catulle Mendès en sus Soirs moroses recogen numerosos lienzos en los que se representan interiores parisinos, sensuales y aristocráticos como el que aquí nos pinta Rubén. Sin salirnos del Parnaso, Francois Coppée nos dejó igualmente numerosas estampas del género en títulos como Les Intimités o Promenades et intérieurs. Como acertadamente indica Rosa de Diego (2000: 659), en Francia esta corriente "llegará al mejor Rimbaud de "En el cabaret verde", "La tunanta", "Sueño para el invierno", "El aparador", etc., siendo el intermediario [...] François Coppée, al que tanto imita, aunque se burle de él, el autor de Una temporada en el infierno". En Hispanoamérica gozó de amplia fortuna entre poetas modernistas anteriores a Darío como Gutiérrez Nájera. 
parnasianismo más atípico, asordinado, asimilado en las lecturas de Armand Silvestre o Mendès, en su retorno a Centroamérica Darío parece haberse rendido definitivamente a los esplendores del Parnasse canónico de Leconte de Lisle y de José María de Heredia, a quien por entonces acababa de descubrir. A imitación suya, y con anterioridad a su estancia en Guatemala, el 5 de diciembre de 1889 había publicado en la revista de Honduras El tren, bajo el epígrafe de "Sonetos áureos", un poema como "El ánfora", que por motivos ignorados no entró a formar parte de la sección homónima del Azul... de 1890. Amén de una escritura ceñida a los patrones de la Escuela, el Darío del segundo Azul... presenta, además, el orgullo de la pertenencia a la misma, y no duda en ofrendar a los maestros parnasianos su serie de "Medallones", encomiásticos y teorizantes a partes iguales. El primero de la serie va dirigido nada menos que a Leconte de Lisle, a quien le sigue su querido Catulle Medès. ${ }^{26}$ Valiéndose de análogos procedimientos parnasianos, el resto de ofrendas líricas van dirigidas a figuras ajenas a la Escuela como Walt Whitman, Parodi, Salvador Díaz Mirón -en su vertiente más romántica y cívica-, o el cubano José Joaquín Palma, cuyo "Medallón" participa, como ningún otro, de la iconografía y la idiosincrasia poética del Parnasse $e^{27}$.

${ }^{26}$ El "Medallón" de Leconte se complementa con la nota informativa que Darío le dedicaba al final del volumen, en la cual se exhibe no poca erudición respecto al Parnaso: "Es uno de los más vigorosos poetas franceses. A él escribió Víctor Hugo enviándole uno de sus libros: "Jungamos dextras". Es de la aristocracia de los hombres de letras. Lo cual aísla, según decía Baudelaire al hablar de Gautier. El mismo autor de las Flores del mal dijo de Leconte de Lisle: "Il appartient d'ailleurs à cette famille d'esprits qui ont pour tout ce qui n'est pas supérieur un mépris si tranquille qu'il ne daigne même pas s'exprimer". La "Nota XXX" de Darío a Catulle Mendès reza, por su parte, como sigue: "Este maravilloso conteur y poeta desciende de una familia portuguesa judía. Ha publicado muchas obras que le han dado su título de príncipe de las letras. Víctor Hugo le amó paternalmente. Se casó con la hija de Théophile Gautier y se divorció al poco tiempo. Vive en París". Es de notar cómo Darío, tanto en el apunte dedicado a Leconte de Lisle como en el de Mendès, alude a la opinión que de ambos tenía una firma tan autorizada en Hispanoamérica como la de Víctor Hugo. Acaso, sirviéndose de esta estrategia, el joven nicaragüense dotaba de una suerte de carta de nobleza a sus querencias parnasianas, salvaguardándose así de los críticos que, obsesionados todavía con la voz viril y romántica del viejo Hugo, pudieran tacharle de simple currutaco decadente.

27 Sin duda, este "Medallón" podría inclinarnos a pensar que la obra de José Joaquín Palma (1844-1911) se situaba en la órbita del parnasianismo. Sin embargo, Palma se mantuvo dentro de los márgenes del segundo romanticismo americano, y es la nota doliente, victorhuguesca, del exiliado, mezclada al intimismo becqueriano y al requiebro de álbum femenino, aquella que se percibe con mayor continuidad en sus versos, recogidos en el volumen Poesías de J. Joaquín de la Palma (Tegucigalpa, 1882). Ello no quita que Palma conociera a los poetas parnasianos, tal como podemos comprobar en su reseña a la obra de Darío A. de Gilbert, publicada en La Bandera Nacional de Guatemala el 19 de abril de 
En fin, toda la serie de "Notas" finales incluidas por Darío en esta segunda edición de $A z u l \ldots$ nos revelan a un poeta absolutamente prendado de la Escuela parnasiana. Sus acotaciones al prólogo de Eduardo de la Barra son un claro indicio de ello: a las preguntas del chileno sobre la hipotética adhesión de Darío al decadentismo, el propio nicaragüense responde al fin y aclara la cuestión con total rotundidad:

No lo creo [que sea decadente]. Admiro el delicado procedimiento de esos refinados artistas que hoy tiene Francia, pero bien sé hasta donde llegan sus exageraciones y exquisiteces. Entre José María de Heredia, parnasiano, y Mallarmé, Valabrègue, u otros decadentes, me quedo con el rey de los sonetistas.

¿Quedan dudas sobre un Rubén Darío lúcidamente parnasiano, al menos a la altura de 1890? Su reciente entusiasmo por José María de Heredia parece por entonces no tener límite. Ya en su artículo "La poesía castellana contemporánea", publicado en La Unión de San Salvador el 18 de marzo de 1890, se había referido al parnasiano cubano-francés como al "Rey de los sonetistas" (Sequeira, 1964: 311). Tres años antes del triunfo de Les Trophées en Francia y del inicio de su gloriosa recepción en la literatura hispánica, Rubén Darío supo calibrar la imponente lírica herediana a través de su lectura en las colecciones del Parnasse contemporain y en las múltiples publicaciones periódicas que venían presentando, desde tiempo atrás, aquellos brillantes sonetos. Su asimilación por parte de Darío se percibe de manera cabal en el precitado "Medallón" dedicado a Palma, cuyos motivos centrales están muy presentes en algunos poemas de Heredia como "Sur le Pont-Vieux" o "Le Vieil orfèvre" ${ }^{28}$. Por otra parte, Juan Ramón Jiménez (1946: 19) hablaba de cierto

1890: "Si [Darío] hubiera vivido en París en estos últimos años, pertenecería a los parnassiens. Habría escrito y cenado en el Barrio Latino con León Dierx, Ernest d'Hervilly, Albert Glatigny, Sully-Prudhomme, Catulle Mendès, Armand Silvestre, François Coppée y con nuestro cubano el incomparable José María de Heredia...”. Probablemente, esta reseña dio pie al "Medallón" de Darío, quien consideraría a Palma "uno de los suyos" dado su conocimiento del Parnasse.

28 Ambos sonetos aparecerían sucesivamente en la sección "Le Moyen Age et la Renaissance" de Les Trophées (1893). A la altura de 1890, Rubén Darío podía haberlos conocido a través de otra serie de publicaciones anteriores: "Sur le Pont-Vieux" se integraba, por ejemplo, en Le Livre des sonnets (1875) editado por Charles Asselineau y en el tercer Parnasse Contemporain (1876). Por su parte, "Le Vieil orfèvre" había visto ya la luz en la obra de Charles Davillier Recherches sur l'orfèvrerie en Espagne au Moyen Age et à la Renaissance (1879), en la revista Paris-Moderne en su número del $1^{\circ}$ de abril de 1882 , en la Revue bleue el 19 de diciembre de 1885, en la obra de Jules Lemaitre Les Contemporains ( $2^{\mathrm{a}}$ serie, 1886), en la revista Le Semeur el 25 de febrero de 1888 y en una Anthologie des poètes françaises du XIX siècle de 1888. Véase la "Notice" adjunta en el Dossier que Anny Detalle incluye al final de su edición de Les Trophées, Gallimard, 1981. 
"Medallón" dedicado por Darío a Heredia y luego ausente de Azul...: "Este Heredia fue uno de los más queridos parnasianos, y Rubén Darío lo saludó en un Medallón de los de $A z u l . .$. , que luego he visto suprimido en ediciones posteriores del libro precioso". Sin embargo, este hipotético "Medallón" probablemente no llegara a escribirse nunca, dado que no aparece en ninguna edición de Azul... ni tampoco entre los muchos volúmenes que recogen la poesía inédita del nicaragüense. No sería, en cualquier caso, la primera ni la última vez que al Nobel onubense le fallase la memoria o confundiese ciertos datos. Con "Medallón" o sin él, Heredia y su parnasianismo canónico rigen la poética dariana durante el lustro que transcurre desde la primera edición de Azul... en Valparaíso (1888) hasta la estancia del poeta en París en el verano de 1893. El Darío de su segundo periplo centroamericano, el Darío que pisa España por vez primera en 1892, y pese a la opinión de algunos críticos de su tiempo y del nuestro, era un parnasiano pur-sang que no dudaba en imitar y laurear a José María de Heredia por delante de Mallarmé y de toda la caterva de decadentes y simbolistas ${ }^{29}$.

Tras la publicación en Guatemala de la segunda edición de Azul..., Rubén se traslada a Costa Rica en agosto de 1891. En San José llevaría el poeta una vida placentera: alejado de los turbulentos sucesos acaecidos en los meses anteriores, en noviembre le nace su primogénito, y las revistas y diarios en los que colabora parecen abonarle sin premura sus estipendios ${ }^{30}$. Los poemas que escribe durante sus días costarricenses, una serie de "Oditas" y cancioncillas, significan las primeras tentativas de adaptar a su lírica el influjo de las Odes funambulesques de Banville. “¿Dónde estás?", "Versos negros", "Regalito de boda” y especialmente "Los regalos de Puck. Versos de año nuevo" presentan indudables paralelismos con aquellas otras oditas de Banville, particularmente con el "Préface" que el parisino

${ }^{29}$ Uno de aquellos críticos fue el argentino Domingo Martinto, quien hermanaba al Darío de 1890 con los disidentes de la Escuela, Coppée y Sully-Prudhomme, antes que con Mendès o Heredia: "Se pretende que Vd. imite a los franceses, que ama con especial cariño a Catulle Mendès, y aunque estoy conforme con ello en lo que se relaciona a la parte plástica, a la factura de sus obras, no pienso lo mismo acerca de su fondo. En Vd. hay mucho más espontaneidad, muchos más quilates de pensamiento [...], y al seguir en algo su modo [...] lo ha hecho con la misma inteligencia que Sully-Prudhomme y Coppée, que más que Vd. aún se dejaron influenciar por la poética y retórica de los parnasianos". "Una carta literaria", La Unión, 17 de mayo de 1890. En Sequeira, 1964: 232-234.

${ }^{30}$ Merecen mencionarse, a este respecto, Costa Rica Ilustrada (1890-1892) y Revista de Costa Rica (1892). En la primera de ellas, fundada por Próspero Calderón, aparecieron algunos poetas modernistas, aparte de Darío, como Gutiérrez Nájera y Julián del Casal, al tiempo que se tradujeron textos de poetas románticos y parnasianos -Coppée y Catulle Mendès-. La Revista de Costa Rica contó también con la colaboración y el apoyo de Rubén, e igualmente presentó algunas versiones de románticos y parnasianos como Théodore de Banville y François Coppée. 
coloca al comienzo de la sección "Les folies-nouvelles": "Te voilà ! Nous pouvons encor / Te dévider tout le fil d'or / De la bobine! / En un rêve matériel, / Nous te montrerons Ariel / Et Colombine...". Darío adecua perfectamente la versificación y el elástico decir banvillesco a la prosodia castellana, su tono dinámico y el trasfondo emocional en el que se desenvuelven los figurines de la Commedia dell'Arte y del shakesperiano A Midsummer Night's Dream: "Adquiere, de un moscardón, / un ala limpia y hermosa, / Flabel que dará a la esposa / de Oberón. [...] // Fue de vuelo Puck. De pronto / a Colombina encontró, / y junto a ella, hecho un tonto, / a Pierrot...".

\section{Primera estancia en Europa. Darío en Madrid y en París (1892-1893)}

En la primavera de 1892, muy mermada su economía, Darío se vio obligado a abandonar Costa Rica y regresar a Guatemala. Fue allí donde recibió la noticia de su incorporación a la delegación que Nicaragua enviaba a España para asistir a los actos organizados con motivo del cuarto Centenario del descubrimiento de América. En julio de 1892 desembarca en La Habana: una breve escala que le servirá para conocer a su admirado Julián del Casal, dando así inicio a una amistad pronto truncada por la prematura muerte del cubano. Con él comparte horas de bohemia en la redacción de La Habana elegante, donde improvisa poemas de aire banvillesco como "La negra Dominga". Por fin, en agosto, Rubén Darío pisa por vez primera tierra española. Residirá en Madrid sólo unos meses, aunque en la Corte tendrá tiempo de tomar contacto con los grandes nombres de la literatura del momento: Campoamor, Menéndez Pelayo, Núñez de Arce, Pardo Bazán y sobre todo el malagueño Salvador Rueda.

Rueda, a quien por entonces admira y en quien ve a un compañero de armas en la lucha por el modernismo, acoge a Rubén como a la gran promesa de la poesía española de ultramar, le da su apoyo y amistad y lo introduce en los círculos literarios más importantes de Madrid, como la tertulia de Juan Valera. Por mediación de Rueda, Darío publicó su primer poema en España, "Elogio de la seguidilla" -en El Imparcial-, con dedicatoria expresa para el malagueño. Su amistad vive días felices. El nicaragüense llevó a España algunos ejemplares de la segunda edición de $A z u l . .$. , y según puede comprobarse en uno conservado en la Biblioteca Nacional, Rueda se cuenta entre los agraciados con tan preciado regalo si bien con el tiempo se lo cedería a Juan Ramón Jiménez...- ${ }^{31}$.

La primera etapa de Rubén en nuestro país coincide con el momento álgido de su parnasianismo. En la España que desfila antes sus ojos se funden y confunden sus propias expectativas con aquellas que le genera la lectura del Voyage en

31 Así reza la dedicatoria de Darío en el volumen conservado en la BNE: "A mi queridísimo y admirado Sal / vador Rueda, enemigo de los [j] ohtumbas, / Recuerdo y Cariño / Rubén Darío / Madrid, 6 de setiembre del 92". 
Espagne de Gautier, como bien indicaba Arturo Marasso (1973: 108): "Gautier es ahora un idioma que Darío habla. A medida que leía el Viaje por España, Rubén recogió imágenes, palabras preciosas, sugestiones, y se forjaba la visión de una Andalucía romántica y legendaria" ${ }^{32}$. Compárese, en este sentido, el hispanismo de los posteriores Cantos de vida y esperanza con aquella parnasiana "Canción de España" que escribe por entonces en Madrid: "Existe en el salón de porcelana / Del Palacio Real una Diana / Labrada en alabastro. Es blanca y bella. / La divina doncella. // Decora el borde fino de una mesa. / Al mirarla he pensado / En la dulce princesa / Que allí la joven frente ha reclinado...". El parnasianismo que el joven poeta había traído de las Américas no fue mal recibido, en general, por la élite de las letras madrileñas. "Friso" apareció por entonces en La Ilustración Española y Americana, con lo que eso supone en cuanto a su aceptación en el sistema literario imperante. Según confesaba el propio Rubén en las "Dilucidaciones" que abren $E l$ canto errante (1907), habría de dejar España "no sin que antes en las tertulias de Valera se aplaudiesen y se criticasen algunos de los que llamaban mis atrevimientos líricos, que eran entonces [...] apenas de un modesto parnasianismo". En noviembre de 1892 Darío se embarca de nuevo rumbo a Nicaragua, no sin antes agradecer el apoyo de Salvador escribiéndole el célebre "Pórtico" para su poemario En tropel. Cantos españoles, luego incluido en Prosas profanas.

Tras pasar ese otoño de 1892 y el invierno de 1893 en su país, el poeta se encuentra en abril en Panamá, donde recibe la noticia de su nombramiento como Cónsul honorífico de Colombia en Buenos Aires. Antes de partir a la Argentina, y luego de una breve escala en Nueva York para conocer a su admirado José Martí, Rubén Darío cumple por fin el sueño de todo poeta modernista: viajar a París. Durante su verano parisino de 1893, Rubén se relaciona con otros literatos hispanos como Alejandro Sawa y el guatemalteco Enrique Gómez Carrillo, a quien ya conocía desde 1890 cuando compartieron tribuna en El Correo de la Tarde. Ambos contactos resultarían a la postre capitales para la ampliación de sus horizontes literarios, especialmente el que mantuvo con el segundo. Iniciado, antes que él, en los misterios de la literatura simbolista, Gómez Carrillo introduce a Rubén en un París literario que por aquellos días se dividía en dos realidades bien distintas: por un lado, estaba la "oficialidad" del Parnasse triunfante, bien asentado en la Academia, en la Ópera y en las redacciones de los principales diarios. Y por el otro estaban las vanguardias decadentes y simbolistas, la bohemia: la modernidad, en suma, pues a ojos de los Verlaine, Mallarmé, Moréas y sus jóvenes edecanes, el parnasianismo había quedado ya obsoleto, más allá de sus indudables valores

${ }^{32}$ A continuación recoge Marasso un gran número de reminiscencias del léxico y las imágenes que Darío podría haber tomado de la obra de Gautier para construir su poema "Pórtico", tentativa de dominio de la paleta del parnasiano aplicada a su propia visión de España y, sobre todo, de la Andalucía colorista que encarnaba la poesía de Salvador Rueda. 
poéticos.

En títulos como Esquisses (1892) y Sensaciones de arte (1893), Gómez Carrillo venía dando a conocer por vez primera al público hispánico los nombres y al arte sugestivo de Verlaine, Moréas, Wilde, Huysmans, etc. En esta última obra presentó una importante reseña de los Trofeos de Heredia en la cual se hacía eco de la posición del Parnaso en 1893, afirmando que pese a la belleza de sus obras, la Escuela estaba desfasada, ajena al impulso primario que latía en el origen del arte nuevo, decadente y el simbolista:

La poesía parnasiana, marmórea, impasible, no dice ya gran cosa a nuestras almas enfermas; y los escritores que cincelan con frialdad los versos, como si fuesen ánforas, nos son indiferentes. Algunos críticos achacan este desdén a la influencia de la moda, pero en realidad Nuestra Señora del Capricho no tiene nada que ver en el asunto y sólo se trata de nuestras almas. Ahora casi todos tenemos algo de Des Esseintes: nos encantan las coloraciones raras, las orquídeas que parecen flores de porcelana, los perfumes enervantes; adoramos a los poetas malsanos...

He aquí uno de los textos fundamentales para comprender el giro que en seguida habría de dar el modernismo hispánico con la substitución del canon parnasiano por el canon simbolista-decadente. De la mano de Gómez Carrillo, el Darío parnasiano que arriba a París conoce al fin, literaria y personalmente, a varios de los maestros franceses de la nueva estética como Moréas o Charles Morice, quien le iniciaría en el descubrimiento de Verlaine al regalarle su ensayo de 1888, Paul Verlaine. Con ellos aprende y comprende definitivamente que el Parnaso, a esas alturas, había pasado de la vanguardia a la retaguardia, y que era el simbolismo la estética triunfante, tomando sin duda buena nota de ello a su regreso a las Américas. Rubén nunca abandonó sus resabios parnasianos a lo largo y ancho de su obra posterior, pero tras su paso por París ni él, ni su poesía, ni tampoco el modernismo volverían nunca a ser como antes. Eso, sin embargo, ya es otra historia.

\section{BIBLIOGRAFÍA}

ANDERSON IMBERT, E.

1952 "Estudio preliminar" a Darío, R., en Poesías completas. México: FCE.

BANVILLE, Théodore de.

1972 Oeuvres. I. Odes funambulesques. II. Les Stalactites. Odelettes. Amethystes. Le Forgeron. III. Occidentales. Rimes doreés. Rondels. La Perle. IV. Idylles prusiennes. Riquet à la houppe. V. Les Cariatides. Roses de Noël. VI. Le sang de la coupe. Trente-six ballades joyeuses. Le Baiser. VII. Les Exilés. Les Princesses. 
Reimpresión de la edición de París, 1890-1909. Paris: Genève, Slatkine Reprints.

COPPÉE, François.

1880 Poésies: 1869-1874. Les Humbles. Écrit pendant la siège. Plus de sang. Promenades et intérieurs. Le Cahier Rougé. Parfis: Alphonse Lemerre.

1881 Poésies: 1864-1869. Le Reliquaire. Intimités. Poèmes modernes. La grève des Forgerous. Paris: Alphonse Lemerre.

DARÍO, Rubén.

1917-1919 Obras Completas. 22 tomos. Madrid: Ed. Mundo Latino.

1950-1955 Obras Completas. 5 Tomos. Madrid: Afrodisio Aguado.

1989 El modernismo y otros ensayos. Ed. de Iris M. Zavala. Madrid: Alianza Editorial.

1999 Autobiografía. España contemporánea. México: Ed. Porrúa.

2007 Obras Completas. Volumen I: Poesía. "Opera Mundi”. Barcelona: Galaxia Gutenberg-Círculo de Lectores.

DE DIEGO, Rosa.

2000 "Introducción" a Antología de la poesía romántica francesa. Madrid: Cátedra.

GAUTIER, Théophile.

2004 Oeuvres poétiques complètes. Ed. establecida por Michel Brix. Paris: Bartillat.

GAVIDIA, Francisco.

1974 Obras Completas. Recopilación de José Mata Gavidia. San Salvador: Dirección de Publicaciones del Ministerio de Educación de El Salvador.

GUANDIQUE, José Salvador.

1965 Gavidia, el amigo de Darío. San Salvador: Dirección General de Publicaciones del Ministerio de Educación.

HEREDIA, José-María de.

1981 Les Trophées. Ed. de Anny Detalle. Paris: Gallimard.

HERNÁNDEZ AGUIrre, Mario.

1968 Gavidia. Poesía, Literatura, Humanismo. San Salvador: Dirección de Publicaciones del Ministerio de Educación.

JIMÉNEZ, Juan Ramón.

1946 "El modernismo poético en España y en Hispanoamérica", Revista de América, VI, pp. 17-30.

LECONTE DE LISLE, Charles.

1985 Poèmes barbares. Ed. de Claudine Gothot-Mersch. Paris: Gallimard.

1994 Poèmes antiques. Ed. de Claudine Gothot-Mersch. Paris: Gallimard. 
LLOPESA, Ricardo.

1989 "Precedentes del modernismo", Turia. Revista cultural, no 12, pp. $15-24$.

1991 "Prologo" a Mendès, C., en Pequeños poemas en prosa. Valencia: Ed. Ojuebuey.

1992 "Pensamiento de otoño de Rubén Darío", Barcarola. Revista de Creación Literaria, (39): 209-215.

1995 "Prólogo" a Mendès, C., en Lesbia. Valencia: Instituto de Estudios Modernistas.

LÓPEZ MORILLAS, Juan.

1944 "El Azul... de Rubén Darío”, Revista Hispánica Moderna, 10, pp. 9-14.

MAPES, Erwin K.

1925 L'influence française dans l'oeuvre da Rubén Darío. Paris: Librairie Ancienne Édouard Champion.

MARASSO, Arturo.

1973 Rubén Dario y su creación poética. Buenos Aires: Editorial Kapelusz.

MARTínEZ, José María.

1998 "Introducción” a Darío, R., en Azul... / Cantos de vida y esperanza. Madrid: Cátedra.

MENDÈs, Catulle.

1885 Les poésies: Philoméla, Sonnets, Pantéleïa, Sérénades, Pagode, Soirs moroses, Contes épiques, Hespérus, Interméde, Le Soleil de Minuit. Paris: P. Ollendorff.

PÉREZ, Alberto Julián.

1992 "Los comienzos poéticos de Darío: Romanticismo y Parnaso", Anales de Literatura Hispanoamericana,vol. 21, pp. 483-494.

PHILLIPS, Allen W.

1974 "Rubén Darío y sus juicios sobre el Modernismo", en H. Castillo (ed.), Estudios críticos sobre el modernismo. Madrid: Gredos.

PRUDHOMME, Sully.

1872 Poésies 1866-1872. Les Épreuves. Les Écuries d'Augias. Croquis italiens. Les solitudes. Impressions de la guerre. Paris: Alphonse Lemerre.

1900 Poésies 1865-1866. Stances et poémes. Paris: Alphonse Lemerre.

REVEL, Émile.

1942 Leconte de Lisle animalier et le gout de la zoologie au XIXe siècle. Marseille: Imp. du Sémaphore.

ROCUANT, M. L.

[s.f.] Los líricos y los épicos. Madrid: Rivadeneyra. 
SELLÉS, Carmen Luna.

2002 La exploración de lo irracional en los escritores modernistas hispanoamericanos. Literatura onírica y poetización de la realidad. Santiago de Compostela: Universidade de Santiago de Compostela. Santiago de Compostela.

SEQUEIRA, Diego Manuel.

1945 Rubén Dario criollo, o Raiz y médula de su creación poética. Ed. Guillermo Kraft. Buenos Aires.

1964 Rubén Dario criollo en El Salvador: segunda estada o atalaya de su revolución poética. Nicaragua: Editorial Hospicio. Nicaragua

SilVA CASTRO, Raúl.

1934 Obras desconocidas de Rubén Dario escritas en Chile y no recopiladas en ninguno de sus libros. Santiago de Chile: Prensas de la Universidad de Chile.

1966 Rubén Dario a los veinte años. Santiago de Chile: Editorial Andrés Bello.

SILVESTRE, Armand.

1880 Poésies 1866-1872. Rimes neuves et vieilles. Les Renaissances. La Gloire du souvenir. Paris: Alphonse Lemerre.

TORUÑO, Juan Felipe.

1969 Gavidia. Entre Raras Fuerzas Étnicas. San Salvador: Dirección de Publicaciones del Ministerio de Educación.

UHRHAN de Irving, E.

1970 "Rubén Darío y Narciso Tondreau, íntimos amigos de Chile", en Actas del Tercer Congreso Internacional de Hispanistas, coord. por Carlos H. Magis, pp. 883-892. 